\title{
Brain natriuretic peptide predicts mortality in the elderly
}

\author{
Thomas Wallén, Sten Landahl, Thomas Hedner, Kazuwa Nakao, Yoshihiko Saito
}

\begin{abstract}
Objective-To study whether prospective measurements of circulating concentrations of brain natriuretic peptide (BNP) could predict mortality in the general elderly population.

Design and setting-Circulating BNP was measured in a cohort of 85 year olds from the general population who were followed up prospectively for five years as part of a longitudinal population study, "70 year old people in Gothenburg, Sweden".

Patients-541 subjects from the 85 year old population in Gothenburg. All subjects were investigated for the presence or absence of cardiovascular disorder such as congestive heart failure, ischaemic heart disease, hypertension, and atrial fibrillation. Venous plasma samples were obtained for BNP analysis.

Main outcome measure-Overall mortality during the prospective follow up period.
\end{abstract}

Results-Circulating concentrations of BNP predicted five-year mortality in the total population $(P<0.001)$. In subjects with a known cardiovascular disorder, five-year mortality was correlated with increased BNP concentrations $(P<0.01)$. Increased BNP concentrations predicted five-year mortality in subjects without a defined cardiovascular disorder $(P<$ 0.05).

Conclusions-In an elderly population, measurements of BNP may add valuable prognostic information and may be used to predict mortality in the total population as well as in patients with known cardiovascular disorders. In subjects without any known cardiovascular disorder, BNP was a strong and independent predictor of total mortality.

(Heart 1997;77:264-267)

Pharmacology,

Sahlgrenska Hospital,

University of

Gothenburg, Sweden

T Hedner

Second Division,

Department of

Medicine, Kyoto

University School of

Medicine, Japan

K Nakao

Y Saito

Correspondence to:

Dr T Wallén, Department of

Geriatric Medicine, Vasa

Hospital, S-411 33,

Gothenburg, Sweden.

Accepted for publication

2 December 1996 chronic heart failure, ${ }^{3}$ acute myocardial infarction, ${ }^{4}$ and essential hypertension with left ventricular hypertrophy. ${ }^{5}$

In selected patient groups, it has been sug- $\approx$ gested that measurements of ANF in plasma $\overrightarrow{0}$ could be used as a predictor of the prognosis in patients with heart failure ${ }^{6}$ and in patients $\vec{\omega}$ with acute myocardial infarction. ${ }^{7}$ It is not yet known whether circulating concentrations of BNP may provide such a prognostic information in the general population. In order to $\omega$ evaluate this, we have analysed BNP in a representative sample of 541 very elderly persons 음 (85 year old males and females) from the general population of the city of Gothenburg, $?$ Sweden.

\section{Methods}

\section{STUDY POPULATION}

The longitudinal population study "70 year old people in Gothenburg, Sweden" started in 1971-72 after systematic sampling of subjects born in 1901-02. The general design of the $\triangle$ study $^{8}$ has been described previously. In this study, 541 subjects were examined at the age of 85 and the mortality data are from the prospective five years follow up period after age 85 .

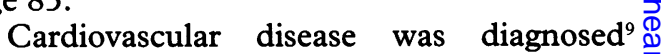
according to the following criteria. Congestive heart failure $(n=119)$ was defined as: all 3 three of the symptoms cyanosis, dyspnoea, and oedema; two of these symptoms in combination with an increased total heart volume 0 related to body surface area $\left(\geqslant 600 \mathrm{ml} / \mathrm{m}^{2}\right.$ ? BSA in men and $\geqslant 550 \mathrm{ml} / \mathrm{m}^{2}$ in women without digitalis or diuretic treatment; $\geqslant 500=$ $\mathrm{ml} / \mathrm{m}^{2}$ BSA in men and $\geqslant 450 \mathrm{ml} / \mathrm{m}^{2}$ in $\sigma$ women with such treatment); pulmonary con- 0 gestion defined as central dilated pulmonary N vessels; or an increased heart volume in the 0 absence of systemic hypertension. Ischaemic heart disease $(n=215)$ was defined as either $\stackrel{\complement}{\mathbb{D}}$ presence of angina pectoris according to $\stackrel{\mathcal{C}}{\rightarrow}$ Rose, ${ }^{10}$ or presence of probable ECG evidence 0 of ischaemia as left bundle branch block or major $Q$ waves according to the Minnesota code (Q111-Q128), ST-J depression of $1 \mathrm{~mm} \unrhd$ or more, or a negative $\mathrm{T}$ wave in leads $\mathrm{I}$ and $\mathrm{II}$, CR2-CR7, AVL and AVF. Hypertension (no $=110$ ) was defined as treatment for hypertension or a casual diastolic blood pressure above $110 \mathrm{~mm} \mathrm{Hg}$ (phase IV). Atrial fibrillation (AF, $\mathrm{n}=62$ ) was defined according to the presence of ECG signs. Diabetes mellitus was defined as pharmacological treatment or fasting blood glucose $>8.0 \mathrm{mmol} / \mathrm{l}$. Renal dys- 
function was defined as serum creatinine $>120 \mu \mathrm{mol} / 1$, and creatinine clearance was also estimated." The symptom "dyspnoea" $(n=263)$ was defined as dyspnoea on exercise (two flights of stairs) or orthopnoea.

In order to define a reference group without

Table 1 Distribution of venous plasma concentrations of brain natriuretic peptide $(\mathrm{pg} / \mathrm{ml})$ in the total population, patients with cardiovascular diseases (CVD), and patients without cardiovascular diseases (non-CVD) shown as mean, minimum, and maximum in the first and fifth quintile

\begin{tabular}{lrrrr}
\hline & & Mean & Min & \multicolumn{1}{c}{ Max } \\
\hline Total & Q1 & 6.5 & 1.0 & 11.3 \\
CVD & Q5 & 151.8 & 61.5 & 1103.0 \\
\multirow{2}{*}{ Non-CVD } & Q1 & 6.5 & 1.0 & 11.1 \\
& Q5 & 153.9 & 61.5 & 1103.0 \\
& Q5 & 6.4 & 1.0 & 11.3 \\
& Q5 & 138.8 & 64.6 & 473.0 \\
\hline
\end{tabular}

Figure 1 Brain natriuretic peptide (quintile 1 to 5) and total mortality in the total population of 85 year old subjects $(n=$ 541): survival curves over five years of follow up. $P$ values refer to trend analysis between quintiles and mortality after 12, 24, 36,48 , and 60 months of prospective follow $u p$.

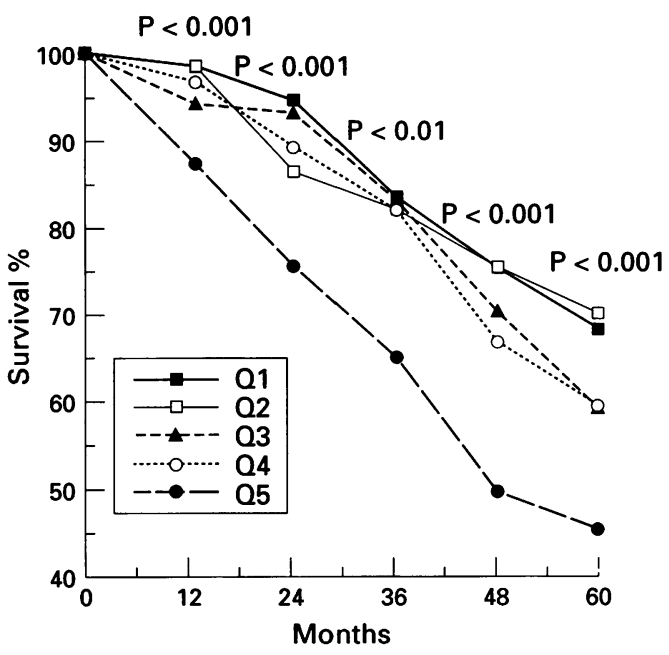

Figure 2 Brain natriuretic peptide (quintile 1 to 5) and total mortality in 85 year old patients with known cardiovascular disorder (ischaemic heart disease, congestive heart failure, atrial fibrillation, and hypertension; $n=$ 326): survival curves over five years of follow up. $P$ values refer to trend analysis between quintiles and mortality after 12,24 36,48 , and 60 months of prospective follow up.

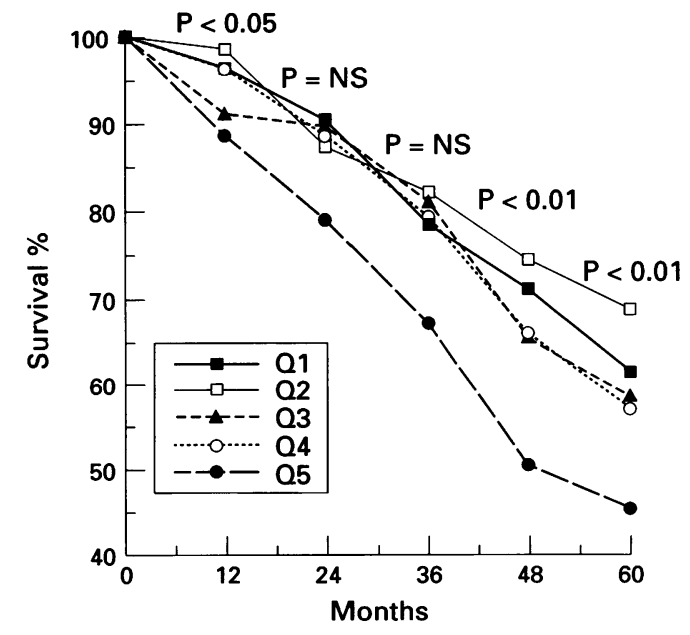

Table 2 Multivariate analysis of the relation between log brain natriuretic peptide (BNP), congestive heart failure (CHF), ischaemic heart disease (IHD), hypertension, dyspnoea, atrial fibrillation, diabetes mellitus, renal dysfunction, and 60 months mortality in the total population

\begin{tabular}{lllll}
\hline Variable & $P$ value & Risk ratio & Lower & Upper \\
\hline LogBNP & $0 \cdot 0020$ & 1.259 & 1.088 & 1.457 \\
Dyspnoea & $0 \cdot 0943$ & & & \\
IHD & $0 \cdot 1553$ & & & \\
Atrial fibrillation & $0 \cdot 2108$ & & & \\
Hypertension & $0 \cdot 4086$ & & & \\
CHF & $0 \cdot 6065$ & & & \\
Renal dysfunction & $0 \cdot 8432$ & & & \\
Diabetes mellitus & 0.8778 & & & \\
\hline
\end{tabular}

cardiovascular disorder $(n=209)$, subjects with congestive heart failure, ischaemic heart disease, hypertension, and atrial fibrillation were excluded from the total population. (Note that one specific patient may have several diagnoses.)

Venous blood samples were taken in the supine position from an antecubital vein after overnight fasting. The samples for BNP were taken into EDTA containing glass tubes on ice water, centrifuged at $+4^{\circ} \mathrm{C}$, and plasma was then immediately frozen and stored at $-70^{\circ} \mathrm{C}$ until analysis.

\section{PLASMA BNP ASSAY}

The plasma BNP concentration was measured from $0.1 \mathrm{ml}$ of plasma without extraction procedure using a highly sensitive immunoradiometric assay (IRMA) (S-1215, Shionogi, Osaka, Japan), as reported previously. ${ }^{12}$ In this assay the minimum detectable quantity of human BNP is $0.5 \mathrm{fmol} / \mathrm{ml}$ and the degree of cross reactivity with a-human ANP is less than $0.001 \%$ on a molar basis. The intra-assay and interassay variation were less than $10 \%$ in this assay system.

\section{STATISTICAL METHODS}

A non-parametric test (permutation test) was used for testing the bivariate correlation with mortality (trend analysis). Stepwise Cox regression model was used for the analysis of association with mortality when controlling for relevant background variables. A P value of less than 0.05 was considered statistically significant. Logarithmic transformation was used in the statistical analysis due to skewed distribution of BNP in the population. Sex was always entered as the first independent varîable in the Cox regression analysis although it is not shown in the results.

\section{Results}

OUTCOME DURING FIVE YEAR PROSPECTIVE FOLLOW UP

The mortality rate in the total study population ( $\mathrm{n}=541)$ during the five year follow up period was $39 \cdot 5 \%$. The mean, minimum, and maximum concentration of venous plasma BNP in the first and fifth quintile in the total population and in the subgroups with and without cardiovascular disorders is shown in table 1 .

In the total population there was a significant correlation between increased circulating concentrations of BNP and one-year mortality $(P<0.001)$, two-year mortality $(P<0.001)$, three-year mortality $(P<0.01)$, four-year mortality $(P<0.001)$, and five-year mortality $(P<$ 0.001 ), as shown in fig 1 . In subjects with cardiovascular disorders such as congestive heart failure, ischaemic heart disease, hypertension, and atrial fibrillation $(n=326)$, increased circulating concentrations of BNP were predictive of the one-year mortality $(P<0.05)$, four-year mortality $(P<0.01)$, and five-year mortality $(P<0.01)$, but not of the two-year and three-year mortality ( $P=N S)$, as shown in fig 2. In the multivariate analysis, BNP was 
Table 3 Multivariate analysis of the relation between log brain natriuretic peptide (BNP), congestive heart failure (CHF), ischaemic heart disease (IHD), hypertension, dyspnoea, atrial fibrillation, diabetes mellitus, renal dysfunction, and 60 month mortality in patients with cardiovascular disorder

\begin{tabular}{lllll}
\hline Variable & $P$ value & Risk ratio & Lower & Upper \\
\hline LogBNP & 0.0182 & 1.240 & 1.037 & 1.483 \\
IHD & 0.0476 & 1.510 & 1.004 & 2.271 \\
Atrial fibrillation & 0.1987 & & & \\
Renal dysfunction & 0.2205 & & & \\
Dyspnoea & 0.2477 & & & \\
Diabetes mellitus & 0.4653 & & & \\
CHF & 0.6929 & & & \\
Hypertension & 0.9799 & & &
\end{tabular}

Figure 3 Brain natriuretic peptide (quintile 1 to 5) and total mortality in 85 year old patients without diagnosed cardiovascular disorder $(n=209)$ : survival curves over five years of follow up. $P$ values refer to trend analysis between quintiles and mortality after $12,24,36,48$, and 60 months of prospective follow up.

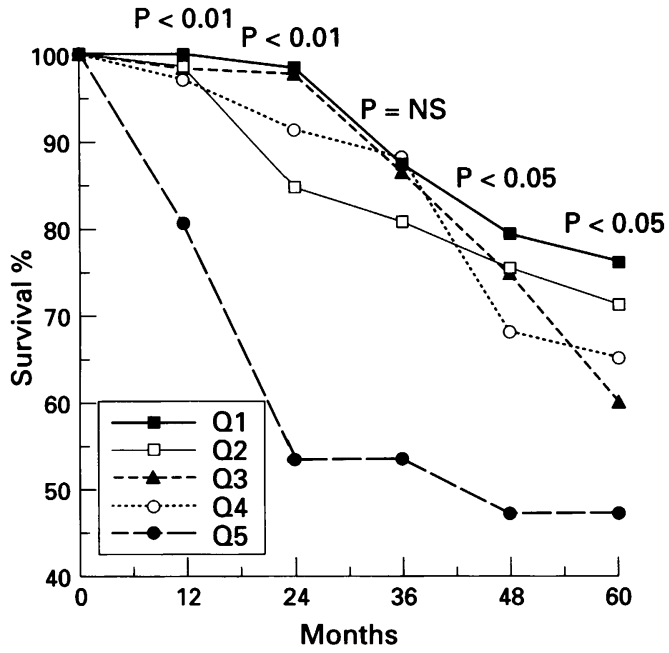

Table 4 Multivariate analysis of the relation between log brain natriuretic peptide (BNP), diabetes mellitus, renal dysfunction, and 60 month mortality in the 85 year old population without defined cardiovascular disorder

\begin{tabular}{lllll}
\hline Variable & P value & Risk ratio & Lower & Upper \\
\hline LogBNP & 0.0228 & 1.382 & 1.046 & 1.826 \\
Renal dysfunction & 0.0410 & 2.019 & 1.029 & 3.962 \\
Diabetes mellitus & 0.2696 & & & \\
\hline
\end{tabular}

associated with mortality independently of background variables such as ischaemic heart disease, congestive heart failure, hypertension, and atrial fibrillation in the total population (table 2) and in the cardiovascular disorder population (table 3 ).

In subjects without defined or known cardiovascular disease at entry, plasma concentrations of BNP were correlated with one-year mortality $(P<0.01)$, two-year mortality $(P<$ $0.01)$, four-year mortality $(P<0.05)$, and fiveyear mortality $(P<0.05)$, but not three-year mortality $(P=N S)$, as shown in fig 3 . The multivariate analysis showed a significant association between five-year mortality and BNP and renal dysfunction (table 4). However, in the univariate analysis, there was no significant association between renal dysfunction and BNP (table 5) and we could not find any significant correlations between estimated creatinine clearance and concentrations of BNP (table 6 ) in these subjects without defined or known cardiovascular disease.

\section{Discussion}

The main finding in our study was that total mortality in this very elderly population was significantly predicted by BNP in patients with
Table 5 Brain natriuretic peptide (BNP) (pg/ml, mean (SD)) in relation to renal dysfunction (serum creatinine $>120 \mu \mathrm{mol} / \mathrm{l}$ ) in the 85 year old population without defined cardiovascular disorder

\begin{tabular}{lrl}
\hline & \multicolumn{1}{l}{$n$} & $B N P$ \\
\hline $\begin{array}{l}\text { Serum creatinine } \\
<120 \mu \text { mol } / 1 \\
\begin{array}{c}\text { Serum creatinine } \\
>120 \mu \mathrm{mol} / 1\end{array}\end{array}$ & 181 & $30 \cdot 0(31 \cdot 4)$ \\
& 20 & $46 \cdot 8(101 \cdot 1) \mathrm{P}=\mathrm{NS}$
\end{tabular}

Table 6 Brain natriuretic peptide in relation to estimated creatinine clearance in subjects without defined cardiovascular disorder

\begin{tabular}{lll}
\hline$n$ & $P$ value & Corr coefficient \\
\hline 200 & 0.126 & -0.079
\end{tabular}

cardiovascular disease, as well as in a patient group without any known cardiovascular disorder at entry. In the multivariate analysis, BNP was the strongest and independent predictor of mortality in this population.

Recent studies have shown that BNP concentrations reflects myocardial infarction size and impaired left ventricular function. ${ }^{13}$ This suggests that measurement of BNP may have clinical value as a predictor of prognosis in cardiovascular disease. In a cross sectional evaluation of the cardiac natriuretic peptides, BNP was the best predictor of increased left ventricular end diastolic pressure and decreased left ventricular ejection fraction. ${ }^{14}$ In a recent study, plasma BNP was strongly and independently associated with long term survival after acute myocardial infarction. ${ }^{15}$ In the present investigation in very elderly subjects from the general population, we have shown that in patients with cardiovascular disorders, high BNP concentrations were significantly associated with increased five-year mortality.

Interestingly, we also found a significant correlation between concentrations of BNP and five-year mortality in subjects without known cardiovascular disorders. In healthy elderly subjects it has been shown that there is impaired left ventricular diastolic function with aging, and an increase in relative heart volume, ${ }^{16}$ supporting the view that increased BNP concentrations in these subjects could be due to left ventricular dysfunction. Diastolic dysfunction may also be important in the pathogenesis of congestive heart failure in the elderly, ${ }^{17}$ and recent data have shown that circulating atrial peptides are significantly increased in symptomless left ventricular dysfunction. ${ }^{1819}$

In our study we showed that increased BNP concentrations correlated significantly with mortality in subjects without known cardiovascular disorders. These subjects might have an asymptomatic cardiovascular disorder resulting in the increased BNP, although such disorders could not be diagnosed during the physical examination, at ECG, or on $x$ ray. In these subjects without known cardiovascular disorders, renal dysfunction was also associated with an increased five-year mortality. In the univariate analysis, we could not find significant correlations between $\mathrm{BNP}$ and renal dysfunction or estimated creatinine clearance. 
This supports the view that the relation between mortality and BNP was independent of renal function.

We conclude that in elderly people, circulating plasma concentrations of BNP predict mortality. In such subjects, BNP may also be a marker for cardiac dysfunction resulting from aging or asymptomatic cardiac disease.

This study was supported by the Swedish Medical Research Council (project No 8642), The Swedish Social Research Council, The Wilhelm and Martina Lundgren Foundation, The Swedish Society of Medicine, and The Göteborg Medical Society. From the gerontological and geriatric population studies in Gothenburg, Sweden. Project leader before 1988, Alvar ies in Gothenburg, Sweden. Project
Svanborg; from 1988 Bertil Steen.

1 Sudoh T, Kangawa K, Minamino M, Matsuo H. A new natriuretic peptide in porcine brain. Nature 1988;332: natriure

2 McGregor A, Richards M, Espiner E, Yandle T, Ikram H. Brain natriuretic peptide administered to man: actions and metabolism. F Clin Endocrinol Metab 1990;70: 1103-7.

3 Mukoyama M, Nakao K, Saito Y, Ogawa Y, Hosoda K, Suga S-I, et al. Increased human brain natriuretic peptide in congestive heart failure. $N$ Engl $7 \mathrm{Med} 1990 ; 323$ : 757-8.

4 Mukoyama $M$, Nakao $K$, Obata $K$, Jougasaki $M$, Yoshimura M, Morita E, et al. Augmented secretion of brain natriuretic peptide in acute myocardial infarction. Biochem Biophys Res Commun 1991;180:431-6.

5 Kohno M, Horio T, Yokokawa K, Murakawa K, Yasunari K-I, Akioka K, et al. Brain natriuretic peptide as a cardiac 29-34.

6 Gottlieb SS, Kukin ML, Ahern D, Packer M. Prognostic importance of atrial natriuretic peptide in patients with chronic heart failure $f m$ Coll Cardiol 1989;13:1534-9.

7 Hall C, Rouleau JL, Moyè L, de Champlain J, Bichet D, Klein $\mathrm{M}$, et al. $\mathrm{N}$-terminal proatrial natriuretic factor. An independent predictor of long-term prognosis after myocardial infarction. Circulation 1994;89:1934-42.
8 Rinder L, Roupe S, Steen B, Svanborg A. Seventy-year-old people in Gothenburg: a population study in an industrialized Swedish city. I. General presentation of the study. Acta Med Scand 1975;198:397-407.

9 Landahl S, Svanborg A, Astrand K. Heart volume and the prevalence of certain common cardiovascular disorders at 70 and 75 years of age. Eur Heart $\mathcal{f}$ 1984;5:326-31

10 Rose GA. The diagnosis of ischemic heart pain and intermittent claudication in field surveys. Bull WHO 1962;27: 645-58.

11 Cockcroft DW, Gault MH. Prediction of creatinine clearence from serum creatinine. Nephron 1976;16: $31-41$

12 Yasue $H$, Yoshimura $M$, Sumida $H$, Kikuta $K$, Kugiyama $\mathrm{K}$, Jougasaki $\mathrm{M}$, et al. Localization and mechanism of secretion of B-type natriuretic peptide in comparison with those of A-type natriuretic peptide in normal subjects and patients with heart failure. Circulation 1994; 90:195-203.

13 Arakawa N, Nakamura $M$, Aoki H, Hiramori $K$ Relationship between plasma levels of brain natriuretic peptide and myocardial infarct size. Cardiology 1994;85: peptide $334-40$.

14 Omland T, Aakvaag A, Vik-Mo H. Plasma cardiac natriuretic peptide determination as a screening test for the detection of patients with mild left ventricular impairment. Heart 1996;76:232-7.

15 Omland T, Aakvaag A, Bonarjee V, Caidahl K, Lie RT, Nilsen $\mathrm{D}$, et al. Plasma brain natriuretic peptide as an indicator of left ventricular systolic function and longterm survival after acute myocardial infarction. Circulation 1996;93:1963-9.

16 Lernfelt B, Wikstrand J, Svanborg A, Landahl S. Aging and left ventricular function in elderly healthy people. $A m \mathcal{F}$ Cardiol 1991;68:547-9.

17 Wong WF, Gold S, Fukuyama O, Blanchette PL. Diastolic dysfunction in elderly patients with congestive heart failure. Am $\mathcal{F}$ Cardiol 1989;63:1526-8.

18 Lerman A, Gibbons RJ, Rodeheffer RJ, Bailey KR, McKinley LJ, Heublein DM, et al. Circulating N-terminal atrial natriuretic peptide as a marker for symptomless left-ventricular dysfunction. Lancet 1993;341:1105-9.

19 Francis GS, Benedict C, Johnstone DE, Benedict C, Johnstone EJ, Kirlin PC, et al. Comparison of neuroendocrine activation in patients with left ventricular dysfunction with and without congestive heart failure: a substudy of the Studies of Left Ventricular Dysfunction (SOLVD). Circulation 1990;82:1724-9. 